\title{
Association analysis of the COL1A1 polymorphism with bone mineral density and prevalent fractures in Polish postmenopausal women with osteoporosis
}

Joanna Dytfeld ${ }^{1}$, Michalina Marcinkowska ${ }^{1}$, Natalia Drwęska-Matelska², Michał Michalak² Wanda Horst-Sikorska ${ }^{1}$, Ryszard Stomski ${ }^{4,5}$

\author{
${ }^{1}$ Department of Family Medicine, Poznan University of Medical Sciences, Poznan, \\ Poland \\ ${ }^{2}$ Department of Biochemistry and Biotechnology, Poznan University of Life Sciences, \\ Poznan, Poland \\ ${ }^{3}$ Department of Computer Science and Statistics, Poznan University of Medical \\ Sciences, Poznan, Poland \\ ${ }^{4}$ Department of Biochemistry and Biotechnology, Poznan University of Life Sciences, \\ Poznan, Poland \\ ${ }^{5}$ Institute of Human Genetics, Polish Academy of Sciences, Poznan, Poland
}

Submitted: 5 March 2014

Accepted: 5 July 2014

Arch Med Sci 2016; 12, 2: 288-294

DOI: $10.5114 /$ aoms.2016.59253

Copyright $\odot 2016$ Termedia \& Banach

\section{Abstract}

Introduction: Polymorphism in the promoter region of collagen type $1 \alpha$ $(C O L 1 A 1)+1245 G / T(S p 1$, rs1800012) was in some studies shown to be relevant for bone mineral density (BMD) and low-energy fracture prediction. The aim of the study was to confirm this finding in a group of postmenopausal women diagnosed with osteoporosis.

Material and methods: We investigated 311 Caucasian women (mean age: $65.2 \pm 9.39$ years) either after low-energy fractures (regardless of the location) or meeting World Health Organization (WHO) criteria for osteoporosis. All patients underwent clinical examination in order to exclude secondary osteoporosis; hip and lumbar spine DEXA was performed (Lunar). The three genotypes of Sp1 polymorphism were determined by RFLP (restriction fragment length polymorphism).

Results: Distribution of COL1A1 genotypes (SS/Ss/ss) agreed with HardyWeinberg equilibrium. No relation between COL1A1 genotypes and hip/ L1-L4 BMD was found. Fractures were reported in $26.3 \%$ of women. Prevalence of low-energy fractures, regardless of the type, was $50.0 \%$ in ss genotype carriers, $26.4 \%$ in SS homozygotes and $23.7 \%$ in Ss heterozygotes. There was no statistically significant recessive or dominant effect of any Sp 1 genotype on fracture prevalence $(p=0.613)$.

Conclusions: We failed to observe that COL1A1 Sp 1 genotypes contribute to $B M D$ determination or are associated with prevalent low-energy fractures in a Polish cohort of postmenopausal osteoporotic women.

Key words: postmenopausal osteoporosis, bone mineral density, fractures, COL1A1 polymorphism.

\section{Introduction}

Osteoporosis is one of the most prevalent chronic conditions in the elderly population. Its progress is silent and lasts for years, with fractures as the most common first manifestation of the disease. In 2000, over

\author{
Corresponding author: \\ Joanna Dytfeld MD, PhD \\ Department \\ of Family Medicine \\ Poznan University \\ of Medical Sciences \\ 49 Przybyszewskiego St \\ 60-355 Poznan, Poland \\ Phone: +48 618691147 \\ E-mail: dytfeld@poczta.onet.pl
}


9 million low-energy fractures were reported worldwide (1.7 million Colles' fractures, 1.6 million hip fractures, and 1.4 million clinically overt vertebral fractures) [1]. Clinical consequences of such fractures, especially the hip, are severe: $50 \%$ of the affected patients lose the ability of unassisted motion; every fifth woman and every third man dies in the first year after the fracture [2].

Given the statistical data and the unquestionable growth in life expectancy, there is a clear need to find reliable markers of poor bone quality. Osteoporosis is a disease of multifactorial etiology, with a strong genetic background. Variance in peak bone mineral density (BMD) has been proven to be genetically dependent in $70 \%$ of cases [3]. Genetic and molecular tests are likely to identify subjects liable to low-energy fractures. Contemporary approaches used to find genes responsible for disease development include candidate gene studies. Numerous genes are being investigated with regard to bone metabolism: genes that encode growth factors and cytokines related to bone turnover (e.g. osteocalcin, transforming growth factor $\beta 1-T G F-\beta 1$ ), encoding components of bone matrix (bone morphogenetic protein 2 - BMP-2, LDL receptor-related protein 5 - LRP5, osteoprotegerin), and genes related to receptor proteins of calciotropic hormones (vitamin D receptor - VDR, parathormone receptor - PTHR) [4-7]. The list also includes the gene that encodes the major bone protein type 1 collagen.

Collagen synthesis is complex and therefore prone to mutations. The protein is encoded by two genes - on chromosome 17 and 7 for chains $\alpha 1(\mathrm{I})($ COL1A1) and $\alpha 2(\mathrm{I})$, respectively. Mutations in both of these genes have been demonstrated to be responsible for the autosomal dominant form of osteogenesis imperfecta, with severe osteoporosis [8]. The initial finding related to low bone mass in postmenopausal osteoporosis was reported in 1996 by Grant et al. [9], who described the Sp1 polymorphism in the COL1A1 gene $(+1245 \mathrm{G} / \mathrm{T}$, rs1800012). The change of a single nucleotide $(G \rightarrow T)$ was shown to result in polymorphism in intron 1 , specifically in the binding site for transcription factor Sp1 - a site involved in the regulation of collagen transcription. The presence of the " $\mathrm{s}$ " allele is associated with increased mRNA transcription and a relative rise in the amount of $\alpha 1(\mathrm{I})$ chain when compared to $\alpha 2(I)$ chain. The normal ratio of $\alpha 1$ to $\alpha 2$ is $2: 1$. For heterozygotes of Sp 1 polymorphism this proportion is approximately $2.3: 1$. An increased amount of transcript for $\alpha 1$ chain has been suggested to result in formation of collagen homotrimers, which are represented beside the normal protein [10]. Their presence is the reason for deteriorated bone microarchitecture.

The relationship between COL1A1 gene polymorphism and BMD was previously investigated, but various studies generated discrepant results. Moreover, data on the Polish population are scarce.

The aim of the study was to assess the association of Sp1 polymorphism of the COL $1 A 1$ gene with BMD and fracture prevalence in women with postmenopausal osteoporosis.

\section{Material and methods}

The study group comprised 311 postmenopausal, non-institutionalized Caucasian women from the Wielkopolska region (Poland), patients of the Endocrinology Outpatient Clinic, University Hospital No. 2. The diagnosis of osteoporosis was based on previous low-energy fracture or the WHO criteria (DEXA hip or lumbar $T$-score $<-2.5$ SD). Low-energy fracture was classified as such in cases when the following occurred:

1. Minor trauma or fall from standing height or less, preceding the fracture.

2. Fracture at the age of $\geq 50$.

A subgroup of patients with a history of fracture was subject to further, separate analysis.

In the majority of patients prevalent low-energy fractures were self-reported, and in some cases hospital discharge charts or radiographs were available.

Validity of self-report has been reported to be high in the assessment of hip fracture [11] but lower for vertebral fractures. The latter is believed to result from underestimation of vertebral fractures, which often are either unreported by patients or referred to as non-specific back pain.

All study participants underwent a physical examination, including anthropometric measurements. Medical history was taken and women with suspicion of secondary osteoporosis (e.g. with hyperthyroidism, rheumatoid arthritis, chronic kidney diseases, pituitary gland diseases, taking systemic steroids) were excluded from the study. The studied individuals did not receive any pharmacotherapy for osteoporosis or other drugs influencing bone metabolism. The clinical data are presented in Table I.

Table I. General characteristics of study group $(n=311)$

\begin{tabular}{|lc|}
\hline Parameter & Result \\
\hline Age [years] & $65.2 \pm 9.39$ \\
\hline Body weight $[\mathrm{kg}]$ & $62.4 \pm 11.0$ \\
\hline Height $[\mathrm{m}]$ & $1.589 \pm 0.059$ \\
\hline BMI $\left[\mathrm{kg} / \mathrm{m}^{2}\right]$ & $24.7 \pm 4.32$ \\
\hline BMD FN $\left[\mathrm{g} / \mathrm{cm}^{2}\right]$ & $0.700 \pm 0.088$ \\
\hline BMD LS $\left[\mathrm{g} / \mathrm{cm}^{2}\right]$ & $0.799 \pm 0.126$ \\
\hline
\end{tabular}

Data are presented as mean $\pm S D$ unless otherwise indicated. BMI - body mass index, BMD - bone mineral density, FN-femoral neck, LS - lumbar spine. 
Bone mineral density of the lumbar spine (L1-L4) and the femoral neck (FN) was measured by dual energy X-ray absorptiometry (DEXA) (Lunar, Lunar Inc., Madison, WI, USA). The apparatus was calibrated daily. Measurements were performed using standard procedures.

\section{Genotyping}

DNA was isolated from peripheral blood leukocytes by the guanidinium isothiocyanate method. The PCR reaction was carried out in $20 \mu \mathrm{l}$ with $500 \mathrm{ng}$ of genomic DNA, $50 \mathrm{mM} \mathrm{KCl}, 10 \mathrm{mM}$ Tris- $\mathrm{HCl}(\mathrm{pH}$ 8.3), $1.5 \mathrm{mM} \mathrm{MgCl}, 0.25 \mathrm{mM}$ dNTP, 7.5 pmol of each starter and $0.5 \mathrm{U}$ of Taq polymerase (Sigma).

Conditions for the PCR reaction of the fragment containing intron 1 of collagen $1 \alpha$ gene were as follows: initial denaturation at $94^{\circ} \mathrm{C}$ for $4 \mathrm{~min}, 40 \mathrm{cy}$ cles of amplification (denaturation at $94^{\circ} \mathrm{C}$ for $40 \mathrm{~s}$, starters attachment at $67^{\circ} \mathrm{C}$ for $40 \mathrm{~s}$, starters elongation at $72^{\circ} \mathrm{C}$ for $60 \mathrm{~s}$ ). The final stage was elongation at $72^{\circ} \mathrm{C}$ for $5 \mathrm{~min}$. For $\mathrm{Sp} 1$ polymorphism a 260 bp fragment was amplified using the primers F 5'-TAACTTCTGGACTATTTGCGGACTTTTTGG-3' and R 5'-GTCCAGCCCTCATCCTGGCC-3' [9].

The PCR product was then subjected to restriction fragment length polymorphism (RFLP) analysis using Mlsl restrictive enzyme (Fermentas). Owing to the fact that the effectiveness of $P C R$ reaction in that particular case was very low, the division of digestion products was carried out with ALFexpress (Amersham Pharmacia Biotech). Fragments obtained after enzymatic digestion differed only in $18 \mathrm{bp}$. Eight microliters of digestion product was mixed with $4 \mu \mathrm{l}$ of ALFexpress aggravating buffer with internal markers of $113 \mathrm{bp}$ and $525 \mathrm{bp}$. Next, thermal denaturation was performed at $94^{\circ} \mathrm{C}$ for $5 \mathrm{~min}$, and after that the product was immediately chilled on ice. Every $12 \mu \mathrm{l}$ of mixture was put on gel. Disjunction took place in $6.15 \%$ denaturizing polyacrylamide gel, in which the relation of acrylamide to methylenebisacrylamide was $20: 1$. Division conditions were

Table II. Analysis of conformity of genotype distribution of examined polymorphism with HardyWeinberg equilibrium

\begin{tabular}{|lccccc|}
\hline Variable & \multicolumn{3}{c}{$\begin{array}{c}\text { Numbers } \\
\text { observed }\end{array}$} & \multicolumn{2}{c|}{$\begin{array}{c}\text { Numbers } \\
\text { expected }\end{array}$} \\
\cline { 2 - 6 } & & \multicolumn{2}{c}{$\boldsymbol{N}$} & $\%$ & \multicolumn{2}{c|}{$\boldsymbol{N}$} & $\%$ \\
\hline COL1A1 Sp1 & & & & & \\
\hline Genotype & SS & 204 & 65.5 & 205.0 & 65.9 \\
\cline { 2 - 6 } & Ss & 97 & 31.1 & 94.99 & 30.5 \\
\cline { 2 - 6 } & Ss & 10 & 3.2 & 11.00 & 3.5 \\
\cline { 2 - 6 } & & & & $p=0.709$ \\
\hline
\end{tabular}

as follows: temperature $55^{\circ} \mathrm{C}$, power $25 \mathrm{~W}, 0.6 \times$ concentrated buffer TBE. Detection on the ALFexpress set was performed using inducement of fluorescent marker Cy5.

\section{Statistical analysis}

All data are expressed as mean \pm SD, unless otherwise stated. The analyzed data came from the interval and nominal scale. Student's $t$-test was used to compare the two groups, and the Mann-Whitney test was applied in the absence of compliance with the required assumptions (normality and homogeneity of variance). Nominal data were analyzed with the $\chi^{2}$ test. When more than two groups were compared simultaneously, univariate analysis of variance with the Tukey post-hoc test was performed. In case of non-compliance with normal distribution or lack of homogeneity of variance, the Kruskal-Wallis test with Dunn's post-hoc test was performed. All tests were analyzed at the significance level of $\alpha=0.05$. Statistical analysis was performed using Statistica 8.0 software (Stat Soft Inc, Tulsa, USA).

The analyzed genotypes were tested for Hardy-Weinberg equilibrium (http://ihg.gsf.de/cgibin/hw/hwa1.pl and Statistica 8.0).

The association analysis was performed for three possible effects of a given polymorphism: the allele, the recessive and the dominant effect.

In the analysis of associations (case-control type) with the occurrence of fractures, three possible effects of Sp1 polymorphism were also analyzed: the effect of allele dose $\left(\chi^{2}\right.$ Armitage test for a trend), the effect of recessive/dominant action (Pearson's $\chi^{2}$ ) and the odds ratio (OR) were calculated. Additionally, frequencies of alleles were also compared between the groups with and without fractures. In all cases, Pearson's $\chi^{2}$ and the odds ratio for the risk alleles of Sp1 polymorphism were determined. The number of single alleles was calculated as the sum of a double number of alleles in homozygotes (dominant or recessive) and a single number of alleles in heterozygotes.

\section{Results}

Mean age in the study group was $65.2 \pm 9.3$ years. Out of all studied women, 82 (26.3\%) were reported to have a fracture. Clinical data are presented in Table I. The COL1A1 Sp1 genotypes were in Hardy-Weinberg equilibrium $(p=0.709)$. The frequency of genotypes of COL1A1 in the study group is shown in Table II.

There was no statistically significant difference in BMD between carriers of different genotypes of COL1A1 polymorphism (Table III). No evidence for an allele dose effect was found, either for FN or L1-L4 BMD. 
Similarly, no proof of a recessive or dominant effect of any allele was found - the presence of "s" or "S" did not influence BMD in any of the skeletal sites (Table III). The relation between fracture risk and COL1A1 polymorphism is shown in Table IV.

Prevalence of low-energy fractures, regardless of type, was $50.0 \%$ in ss genotype carriers, $26.4 \%$ in SS homozygotes, and $23.7 \%$ in Ss heterozygotes. There was no significant recessive or dominant effect of any Sp1 genotype on fracture prevalence $(p=0.613)$.

The $s$ allele was chosen as the risk allele because its frequency was higher in the fracture group (6\% vs. $4.3 \%$ ), although without statistical significance $(p>0.05)$. Odds ratio for having a fracture in $s$ allele carriers was $1.12(95 \% \mathrm{Cl}$ :

Table III. Association between Sp1 polymorphism COL1A1 and hip/L1-L4 BMD

\begin{tabular}{|c|c|c|c|c|}
\hline \multirow{2}{*}{\multicolumn{2}{|c|}{$\begin{array}{l}\text { COL } 1 A 1 \mathrm{Sp} 1 \\
\underline{\mathrm{FN}}\end{array}$}} & \multicolumn{3}{|c|}{$\begin{array}{c}\text { BMD corrected for age, height, } \\
\text { body mass }\left[\mathrm{g} / \mathrm{cm}^{2}\right]\end{array}$} \\
\hline & & Percentage & BMD & SD \\
\hline \multirow[t]{3}{*}{ Allele dose } & SS & 65.4 & 0.700 & 0.007 \\
\hline & Ss & 30.8 & 0.698 & 0.010 \\
\hline & SS & 3.8 & 0.716 & 0.028 \\
\hline \multicolumn{2}{|c|}{ Significance } & & \multicolumn{2}{|c|}{$p=0.862$} \\
\hline \multicolumn{5}{|c|}{ Recessiveness and dominance effect: } \\
\hline \multirow[t]{2}{*}{ Genotype } & $\begin{array}{l}\text { SS + } \\
\text { Ss }\end{array}$ & 96.2 & 0.700 & 0.006 \\
\hline & SS & 3.8 & 0.716 & 0.028 \\
\hline \multicolumn{2}{|c|}{ Significance } & & \multicolumn{2}{|c|}{$p=0.570$} \\
\hline \multirow[t]{2}{*}{ Genotype } & SS & 65.4 & 0.700 & 0.007 \\
\hline & $\begin{array}{l}\text { Ss }+ \\
\text { sS }\end{array}$ & 34.6 & 0.700 & 0.009 \\
\hline \multicolumn{2}{|c|}{ Significance } & & \multicolumn{2}{|c|}{$p=0.979$} \\
\hline \multicolumn{5}{|c|}{$\begin{array}{l}\text { COL } 1 A 1 \mathrm{Sp} 1 \\
\underline{\mathrm{LS}}\end{array}$} \\
\hline \multicolumn{5}{|c|}{ Allele dose effect: } \\
\hline \multirow{4}{*}{$\begin{array}{l}\text { Allele } \\
\text { dose }\end{array}$} & SS & 66.3 & 0.799 & 0.012 \\
\hline & Ss & 28.9 & 0.797 & 0.017 \\
\hline & ss & 4.8 & 0.820 & 0.043 \\
\hline & & & \multicolumn{2}{|c|}{$p=0.813$} \\
\hline \multicolumn{5}{|c|}{ Recessiveness and dominance effect: } \\
\hline \multirow[t]{2}{*}{ Genotype } & $\begin{array}{l}\mathrm{SS}+ \\
\mathrm{SS}\end{array}$ & 95.2 & 0.798 & 0.010 \\
\hline & SS & 4.8 & 0.820 & 0.043 \\
\hline \multicolumn{2}{|c|}{ Significance } & & \multicolumn{2}{|c|}{$p=0.629$} \\
\hline \multirow[t]{2}{*}{ Genotype } & SS & 66.3 & 0.799 & 0.011 \\
\hline & $\begin{array}{l}\text { SS }+ \\
\text { SS }\end{array}$ & 33.7 & 0.800 & 0.016 \\
\hline Significa & nce & & \multicolumn{2}{|c|}{$p=0.944$} \\
\hline
\end{tabular}

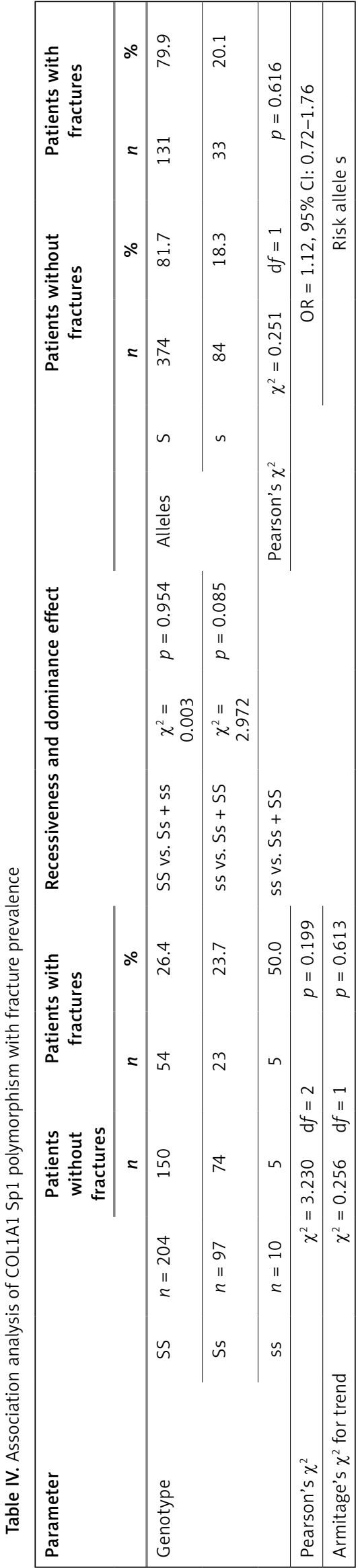


0.72-1.76) when compared to the $S$ allele, but it was not statistically significant.

\section{Discussion}

Different contemporary approaches used in the search for the loci/locus responsible for osteoporosis provide only a partial answer to all the questions posed and confirm the complexity of the genetic trait of osteoporosis. The disease is known to be of polygenic nature, and a single gene has potentially little effect on the phenotype. The phenotype is further modified by environmental factors, which partly explains the lack of reproducibility of molecular analyses in osteoporosis. However, the value of genetic assessment is undoubtedly high-molecular markers do not depend on the time of diagnosis and remain unchanged during an individual's lifetime. They may allow one to identify people with high or even the highest risk for fractures and perhaps help to prevent them. Prevention forms the core component of osteoporosis management.

The hypothesis that the polymorphism within a gene encoding a vital bone protein might serve as a reliable marker of bone quality is very promising. Unlike the VDR gene, the COL1A1 gene affects the final protein product. However, in a homogeneous group of postmenopausal women we did not observe an association between COL1A1 alleles and osteoporotic phenotype measured by $B M D$, both at the hip and the lumbar spine. BMD used in the analyses was age, height and BMI corrected, which highlights the statistical power of this association.

Our results are consistent with several published reports [12-15], although not all of them [16-18], including the GENOMOS study [19], which was a very large, multicenter study involving over 20000 individuals from different European countries. The authors found that ss homozygotes of COL1A1 had significantly lower L1-L4 BMD than other genotypes.

There might be several reasons for the discordance. Uitterlinden et al. concluded that the effect of polymorphism $1245 \mathrm{G} / \mathrm{T}$ on BMD is most marked in the oldest age group (>80) [17]. Women included in our group did not fit into that category $(65.2$ \pm 9.3 years). Secondly, two additional polymorphisms within the collagen gene promoter have been identified in recent years: $-1997 \mathrm{G} / \mathrm{T}$ (PCOL2, rs107946) and -1663indelT (PCOL1, rs2412298). They both were proven to be associated with BMD, lumbar as well as hip [20, 21]. Also, because they are in linkage disequilibrium with the analyzed Sp1 polymorphism, haplotype analysis may provide new information. Gonzalez-Bofill et al. found that haplotype -1997T-1663ins+1245G had a negative impact on BMD, which persisted for the next 10 years, regardless of hormonal replacement therapy [22]. These authors failed to demonstrate increased risk of fracture related to this haplotype. The test group, however, consisted of healthy perimenopausal women. In contrast, Jin et al., in their meta-analysis, demonstrated an association of low bone mass and high fracture risk with different haplotype (-1997G-1663del + 1245T) [23]. In the view of these conflicting reports, it seems likely that regulation of bone biomechanics involves an interaction with other, hitherto unknown, genes and their polymorphic variants.

The frequency of COL1A1 Sp1 genotypes in our group of Caucasian origin was similar to that described by other authors. Langdahl et al. identified $5.3 \%$ ss homozygotes in a group of 372 Danish men and women [18], Uitterlinden et al. reported a rate of $3.3 \%$ in over 1770 women in the Netherlands [17], and Ismail et al. reported 3.5\% among participants of EPOS [24]. Distribution of other Sp1 genotypes was also close to other investigated European populations, as shown by the GENOMOS consortium [19]. Therefore, our group seems representative. Notably, race was shown to impact the distribution of allelic variants. In a group of Korean women with osteoporosis the presence of ss homozygotes was not demonstrated at all [25], similarly to Japanese individuals [26].

Our study indicates that in our selected cohort of Polish women there is no trend toward higher frequency of low-energy fractures (regardless of location) among any genotypes of Sp1 polymorphism. Presumably, the lack of statistical significance was the consequence of a very small number of individuals with ss genotype. However, our results are consistent with the findings of Ralston et al., who evaluated the largest number of osteoporotic individuals of both sexes so far and demonstrated no association between fracture and any Sp1 allele, including s. A significant association was found only for incident vertebral fractures in the female subgroup $(p=0.05, \mathrm{OR}=1.33$ (Cl: 1.0-1.77)) [19]. Despite such convincing data, some authors have reported an association between Sp1 polymorphism and fractures. We were able to show such a trend for prevalent fractures when we included 41 men in our cohort ( $p=0.058$, $\mathrm{OR}=2.92$ (95\% Cl: 0.92-9.29); data not shown) Bernad et al. reported higher fracture (Colles' and vertebral) prevalence in a cohort of Spanish osteoporotic women with ss genotype [27]. Tran et al. reached the same conclusion with regard to hip and vertebral fractures (Australian cohort) [28], and Weichetová et al. did so for Colles' fracture [29]. Also, a 2001 meta-analysis [30], covering 16 Sp1 polymorphism studies, showed that the $s$ allele was strongly associated with susceptibility to fracture $(\mathrm{OR}=1.52,95 \% \mathrm{Cl}: 1.27-1.81)$. 
In 2009, Tran et al. suggested including individual information on carrying the Sp1 allelic variant in the nomogram for osteoporotic fracture risk assessment based on the Dubbo study [28]. Their goal was to assess whether this information could lead to more "efficient" identification of patients at risk of fracture. It turned out that taking the fact of being homozygous for ss into account resulted in a significant (approximately 5\%) change in the threshold of both vertebral and hip fracture risk. Calculated in this way, the risk has changed the indications for antiresorptive therapy.

In the light of our findings, we need to conclude that it is not only BMD that has an absolute effect on fracture risk, but potentially other elements as well. Firstly, there are other factors regulating bone strength that are genetically determined, for example body weight, age at menopause, bone geometry or bone turnover rate. Secondly, most low-energy fractures have been known to occur in women with osteopenia, who do not meet the WHO criteria for osteoporosis. Thirdly, the lack of statistical significance of our calculations might result from insufficient sensitivity of the method. Moreover, our study was not population-based, which might have been a limitation. Still, there is a consensus that the susceptibility to fracture is determined by complex interaction of many genes. Further studies are needed to determine the gene contribution to low-energy fracture risk.

\section{Conflict of interest}

The authors declare no conflict of interest.

\section{References}

1. Johnell O, Kanis JA. An estimate of the worldwide prevalence and disability associated with osteoporotic fractures. Osteoporos Int 2006; 17: 1726-33.

2. Abrahamsen B, van Staa T, Ariely R, et al. Excess mortality following hip fracture: a systematic epidemiological review. Osteoporos Int 2009; 20: 1633-50.

3. Krall EA, Dawson-Hughes B. Heritable and life-style determinants of bone mineral density. J Bone Miner Res 1993; 8: 1-9.

4. Ralston SH. Genetics of osteoporosis. Ann N Y Acad Sci 2010; 1192: 181-9.

5. Boyden LM, Mao J, Belsky J, et al. High bone density due to a mutation in LDL-receptor-related protein 5 . N Engl J Med 2002; 346: 1513-21.

6. Horst-Sikorska W, Dytfeld J, Wawrzyniak A, et al. Vitamin $D$ receptor gene polymorphisms, bone mineral density and fractures in postmenopausal women with osteoporosis. Mol Biol Rep 2013; 40: 383-90.

7. Langdahl BL, Knudsen JY, Jensen HK, Gregersen N, Eriksen EF. A sequence variation: $713-8$ delC in the transforming growth factor-beta 1 gene has higher prevalence in osteoporotic women than in normal women and is associated with very low bone mass in osteoporotic women and increased bone turnover in both osteoporotic and normal women. Bone 1997; 20: 289-94.
8. Marini JC, Forlino A, Cabral WA, et al. Consortium for osteogenesis imperfecta mutations in the helical domain of type I collagen: regions rich in lethal mutations align with collagen binding sites for integrins and proteoglycans. Hum Mutat 2007; 28: 209-21.

9. Grant SF, Reid DM, Blake G, Herd R, Fogelman I, Ralston SH. Reduced bone density and osteoporosis associated with a polymorphic Sp1 binding site in the collagen type I alpha 1 gene. Nat Genet 1996; 14: 203-5.

10. Mann V, Hobson EE, Li B, et al. A COL1A1 Sp1 binding site polymorphism predisposes to osteoporotic fracture by affecting bone density and quality. J Clin Invest 2001; 107: 899-907.

11. Chen Z, Kooperberg C, Pettinger MB, et al. Validity of self-report for fractures among a multiethnic cohort of postmenopausal women: results from the Women's Health Initiative observational study and clinical trials. Menopause 2004; 11: 264-74.

12. McGuigan FE, Reid DM, Ralston SH. Susceptibility to osteoporotic fracture is determined by allelic variation at the Sp1 site, rather than other polymorphic sites at the COL1A1 locus. Osteoporos Int 2000; 11: 338-43.

13. Willing MC, Torner JC, Burns TL, et al. Gene polymorphisms, bone mineral density and bone mineral content in young children: the lowa Bone Development Study. Osteoporos Int 2003; 14: 650-8.

14. Erdogan MO, Yıldız H, Artan S, et al. Association of estrogen receptor alpha and collagen type I alpha 1 gene polymorphisms with bone mineral density in postmenopausal women. Osteoporos Int 2011; 22: 1219-25.

15. Ashford RU, Luchetti M, McCloskey EV, et al. Studies of bone density, quantitative ultrasound, and vertebral fractures in relation to collagen type I alpha 1 alleles in elderly women. Calcif Tissue Int 2001; 68: 348-51.

16. Garnero P, Borel O, Grant SF, Ralston SH, Delmas PD. Collagen lalpha1 $\mathrm{Sp} 1$ polymorphism, bone mass, and bone turnover in healthy French premenopausal women: the OFELY study. J Bone Miner Res 1998; 13: 813-7.

17. Uitterlinden AG, Burger $\mathrm{H}$, Huang $\mathrm{Q}$, et al. Relation of alleles of the collagen type lalpha1 gene to bone density and the risk of osteoporotic fractures in postmenopausal women. N Engl J Med 1998; 338: 1016-21.

18. Langdahl BL, Ralston SH, Grant SF, Eriksen EF. An Sp1 binding site polymorphism in the COLIA1 gene predicts osteoporotic fractures in both men and women. J Bone Miner Res 1998; 13: 1384-9.

19. Ralston SH, Uitterlinden AG, Brandi ML, et al. Large-scale evidence for the effect of the COLIA1 Sp1 polymorphism on osteoporosis outcomes: the GENOMOS study. PLoS Med 2006; 3: e90.

20. Garcia-Giralt N, Nogués X, Enjuanes A, et al. Two new single-nucleotide polymorphisms in the COL1A1 upstream regulatory region and their relationship to bone mineral density. J Bone Miner Res 2002; 7: 384-93.

21. Yazdanpanah N, Rivadeneira F, van Meurs JB, et al. The -1997 G/T and Sp1 polymorphisms in the collagen type I alpha1 (COLIA1) gene in relation to changes in femoral neck bone mineral density and the risk of fracture in the elderly: the Rotterdam study. Calcif Tissue Int 2007; 81: $18-25$.

22. González-Bofill N, Husted LB, Harsløf T. Effects of COLIA1 polymorphisms and haplotypes on perimenopausal bone mass, postmenopausal bone loss and fracture risk. Osteoporos Int 2011; 22: 1145-56.

23. Jin H, Evangelou E, loannidis JP, Ralston SH. Polymorphisms in the 5' flank of COL1A1 gene and osteoporosis: meta-analysis of published studies. Osteoporos Int 2011; 22: 911-21. 
24. Ismail AA, O'Neill TW, Cooper C, et al. Mortality associated with vertebral deformity in men and women: results from the European Prospective Osteoporosis Study (EPOS). Osteoporos Int 1998; 8: 291-7.

25. Han KO, Moon IG, Hwang CS, et al. Lack of an intronic Sp1 binding-site polymorphism at the collagen type I alpha1 gene in healthy Korean women. Bone 1997; 24: $135-7$.

26. Lambrinoudaki I, Kung AW. Absence of high-risk "s" allele associated with osteoporosis at the intronic SP1 binding-site of collagen Ialpha1 gene in Southern Chinese. J Endocrinol Invest 2001; 24: 499-502.

27. Bernad $M$, Martinez ME, Escalona $M$, et al. Polymorphism in the type I collagen (COLIA1) gene and risk of fractures in postmenopausal women. Bone 2002; 30: 223-8.

28. Tran BN, Nguyen ND, Center JR, Eisman JA, Nguyen TV. Enhancement of absolute fracture risk prognosis with genetic marker: the collagen I alpha 1 gene. Calcif Tissue Int 2009; 85: 379-88.

29. Weichetová M, Stepán JJ, Michalská D, Haas T, Pols HA, Uitterlinden AG. COLIA1 polymorphism contributes to bone mineral density to assess prevalent wrist fractures. Bone 2000; 26: 287-90.

30. Mann V, Ralston SH. Meta-analysis of COL1A1 Sp1 polymorphism in relation to bone mineral density and osteoporotic fracture. Bone 2003; 32: 711-7. 